\title{
A recruitment maneuver increases oxygenation after intubation of hypoxemic intensive care unit patients: a randomized controlled study
}

\author{
Jean-Michel Constantin*1, Emmanuel Futier1, Anne-Laure Cherprenet', Gérald Chanques², Renaud Guerin1, \\ Sophie Cayot-Constantin', Mathieu Jabaudon', Sebastien Perbet' , Christian Chartier', Boris Jung², \\ Dominique Guelon³, Samir Jaber² and Jean-Etienne Bazin¹
}

\begin{abstract}
Introduction: Tracheal intubation and anaesthesia promotes lung collapse and hypoxemia. In acute lung injury patients, recruitment maneuvers (RMs) increase lung volume and oxygenation, and decrease atelectasis. The aim of this study was to evaluate the efficacy and safety of RMs performed immediately after intubation.

Methods: This randomized controlled study was conducted in two 16-bed medical-surgical intensive care units within the same university hospital. Consecutive patients requiring intubation for acute hypoxemic respiratory failure were included. Patients were randomized to undergo a RM immediately (within 2 minutes) after intubation, consisting of a continuous positive airway pressure (CPAP) of $40 \mathrm{cmH}_{2} \mathrm{O}$ over 30 seconds (RM group), or not (control group). Blood gases were sampled and blood samples taken for culture before, within 2 minutes, 5 minutes, and 30 minutes after intubation. Haemodynamic and respiratory parameters were continuously recorded throughout the study. Positive end expiratory pressure (PEEP) was set at $5 \mathrm{cmH}_{2} \mathrm{O}$ throughout.
\end{abstract}

Results: The control $(n=20)$ and RM $(n=20)$ groups were similar in terms of age, disease severity, diagnosis at time of admission, and $\mathrm{PaO}_{2}$ obtained under 10-15 L/min oxygen flow immediately before (81 \pm 15 vs $\left.83 \pm 35 \mathrm{mmHg}, P=0.9\right)$, and within 2 minutes after, intubation under $100 \% \mathrm{FiO}_{2}(81 \pm 15$ vs $83 \pm 35 \mathrm{mmHg}, P=0.9)$. Five minutes after intubation, $\mathrm{PaO}_{2}$ obtained under $100 \% \mathrm{FiO}_{2}$ was significantly higher in the $\mathrm{RM}$ group compared with the control group ( $93 \pm 36$ vs $236 \pm 117 \mathrm{mmHg}, P=0.008$ ). The difference remained significant at 30 minutes with $110 \pm 39$ and $180 \pm 79$ $\mathrm{mmHg}$, respectively, for the control and RM groups. No significant difference in haemodynamic conditions was observed between groups at any time. Following tracheal intubation, 15 patients had positive blood cultures, showing microorganisms shared with tracheal aspirates, with no significant difference in the incidence of culture positivity between groups.

Conclusions: Recruitment maneuver following intubation in hypoxemic patients improved short-term oxygenation, and was not associated with increased adverse effects.

Trial registration: NCT01014299

\section{Introduction}

In the ICU, acute respiratory failure is a common problem that usually requires endotracheal intubation [1]. Airway management in critically ill patients, from intuba-

* Correspondence: jmconstantin@chu-clermontferrand.fr

${ }^{1}$ General ICU, Department of Anesthesiology and Critical-Care, Estaing

Hospital, University Hospital of Clermont-Ferrand, 1 Place Lucie Aubrac, 63000 Clermont-Ferrand, France

Full list of author information is available at the end of the article tion to extubation, remains a high-risk procedure $[2,3]$. Endotracheal intubation is a well-known cause of marked changes in respiratory mechanics and gas exchange $[4,5]$. When intubation is used to treat respiratory failure, underlying patient pathology can increase such modifications and the reduction in lung volume results in deep hypoxemia after intubation. Moreover, mechanical venti- 
lation applied to a collapsed and/or infected lung increases the risk of ventilator-induced lung injury $[6,7]$.

Baillard and colleagues have recently shown that preoxygenation with non-invasive ventilation (NIV) is more effective at reducing arterial oxyhemoglobin desaturation after intubation than the usual method [8]. The increase in oxygenation in the NIV group was still significant 30 minutes after intubation. The authors emphasized that alveolar recruitment was seen during preoxygenation with NIV. Recruitment manoeuvres (RMs), which consist of transient increases in inspiratory pressure $[9,10]$, reduce anesthesia-induced lung collapse and hypoxemia [11]. During early acute respiratory failure, RMs increase oxygenation and lung volume, and may reduce lung edema $[9,12]$. Some authors have suggested that there is a potential benefit of an early RM after induction of anesthesia in the operating room [11]. To date, however, no study has evaluated the short-term effect of a RM performed early after intubation in critically ill patients.

RMs can damage or transiently alter the integrity of the alveolar-capillary barrier and promote transient bacterial translocation in animal models $[13,14]$. However, these hypotheses remain unanswered in humans [15].

Therefore, our aim was to determine whether a RM, performed immediately after intubation, was more effective compared with standard management strategies at reducing short-term hypoxemia in hypoxemic patients requiring intubation for invasive ventilation in the ICU. We also aimed to evaluate some aspect of the safety of the procedure.

\section{Materials and methods}

The study design was approved by our local ethics committee (Comite de Protection des Personnes dans la Recherche Biomedicale), and written informed consent was obtained from each patient or the patient's next of kin or legal representative. In emergency situations, delayed consent from patients or family was authorized. We generated a random-number table using a personal computer, and employed this table to prepare envelopes for random patient allocation. The envelopes were opaque, sealed, and numbered to ensure treatment concealment and sequential use. The envelopes were transferred one by one in the second ICU and thereafter opened when a patient was included.

\section{Study population}

Adult patients were recruited in two medicosurgical ICUs of the same French University hospital of Clermont-Ferrand and were considered eligible if they met two criteria: acute hypoxemic respiratory failure requiring intubation; and hypoxemia, defined as a partial pressure of arterial oxygen $\left(\mathrm{PaO}_{2}\right)$ less than $100 \mathrm{mmHg}$ under a high fraction of inspired oxygen $\left(\mathrm{FiO}_{2}\right)$ mask driven by at least $10 \mathrm{~L} / \mathrm{min}$ oxygen [8]. Encephalopathy or coma, a need for cardiac resuscitation, hyperkalemia of more than $5.5 \mathrm{mEq} / \mathrm{L}$ (contraindication to the succinylcholine use), acute brain injury, or recent thoracic surgery were exclusion criteria. Intubation was performed after failure of either oxygen supplementation alone or non-invasive respiratory support. Acute physiologic status (Simplified Acute Physiology Score II) [16], preexistent illnesses (McCabe score) as non-fatal (score of 1), ultimately fatal (score of 2) or rapidly fatal disease (score of 3) [17] and chronic health evaluation (Knaus score) [18] were evaluated.

\section{Study design}

The design of the study is shown in Figure 1. During the pre-inclusion period (at least 10 minutes to a maximum of 30 minutes), each patient wore a high $\mathrm{FiO}_{2}$ mask, driven by 10 to $15 \mathrm{~L} / \mathrm{min}$ oxygen, and was randomly assigned to the control or RM group. Preoxygenation was performed for a three-minute period before standardized rapid-sequence intubation. Preoxygenation employed a non-rebreather bag-valve mask driven by $15 \mathrm{~L} /$ min oxygen. Patients were allowed to breathe spontaneously, with occasional assistance (the usual preoxygenation method). For patients who had received ineffective treatment with NIV before enrolment in the study, preoxygenation was performed with NIV [8]. Standardized rapid-sequence intubation (ketamine $2 \mathrm{mg} / \mathrm{kg}$; succinylcholine $1 \mathrm{mg} / \mathrm{kg}$; laryngoscopy with a Macintosh size 3 or 4 blade, and cricoid pressure to secure the airway) was performed by a senior physician. For patients who had been preoxygenated with NIV, pressure support ventilation was delivered by an ICU ventilator (Evita II Dura ventilator; Dräger, Lübeck, Germany; or a Servo 300 instrument; Siemens, Solna, Sweden). Intubation conditions were reported using an intubation difficulty scale [19]. After oral intubation, each patient was mechanically ventilated, with a tidal volume of 6 to $8 \mathrm{~mL} / \mathrm{kg}$, a respiratory rate of 20 to 25 breaths/minute, a positive end-expiratory pressure (PEEP) of $5 \mathrm{cmH}_{2} \mathrm{O}$, and an $\mathrm{FiO}_{2}$ of $100 \%$.

For patients in the control group, ventilator settings were not modified. For patients in the RM group, an RM consisting of a continuous positive airway pressure (CPAP) of $40 \mathrm{cmH}_{2} \mathrm{O}$ for 30 seconds was applied. The RM was performed no more than two minutes after intubation. If systolic blood pressure decreased below 60 $\mathrm{mmHg}$, RM was interrupted. In both groups, after intubation, if systolic blood pressure was below $60 \mathrm{mmHg}$ or the heart rate less than 40 beats per minute, patients were withdrawn from the study.

\section{Measurements}

Pulse oxymetry $\left(\mathrm{SpO}_{2}\right)$ was continuously monitored throughout the procedure (Oxypleth 520A instrument; 


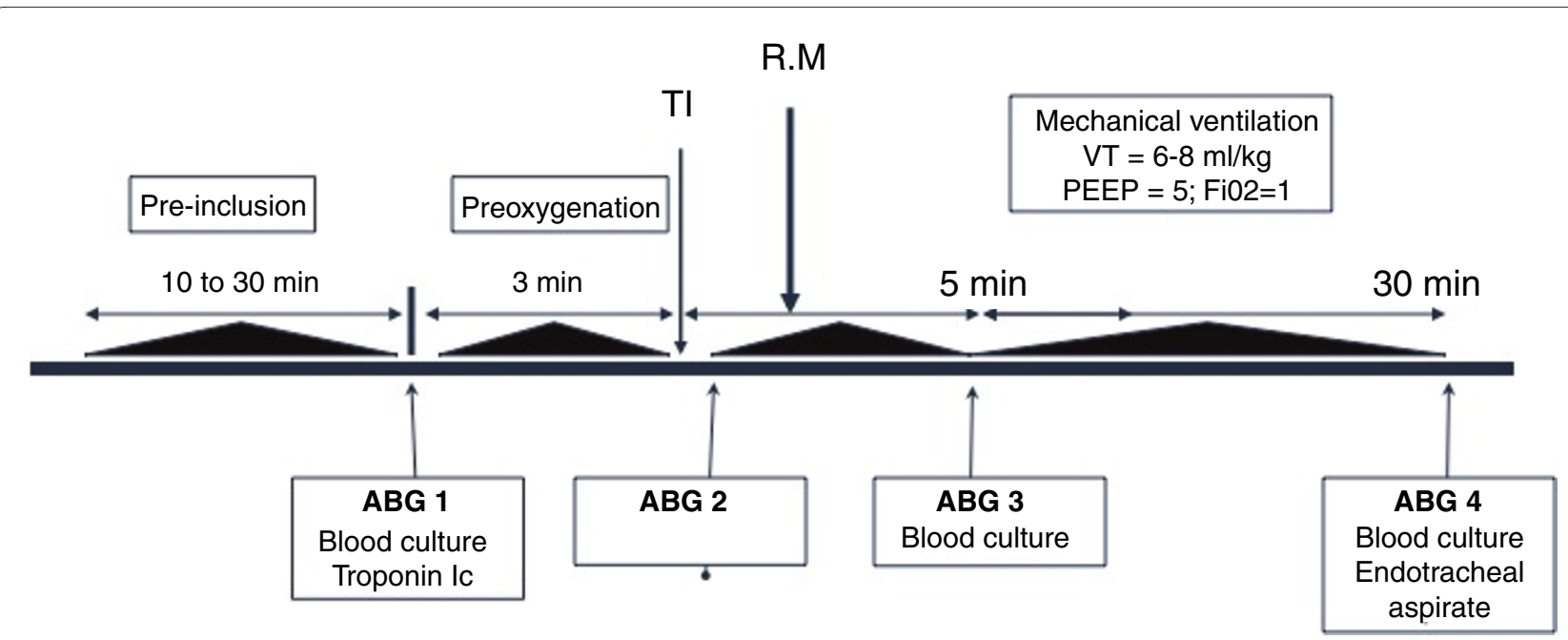

Figure 1 Design of the study. During the inclusion period, patients were randomized to a control or recruitment manoeuvre (RM) group. Clinical parameters were recorded and arterial blood gases (ABG 1) sampled at inclusion. Preoxygenation was performed for a three-minute period. Immediately after tracheal intubation (TI), a second set of ABG measurements were taken (ABG 2). Less than two minutes after intubation, an RM was performed (RM group); no RM was administered to patients in the control group. Protective mechanical ventilation with positive end-expiration pressure (PEEP) at $5 \mathrm{cmH}_{2} \mathrm{O}$ was commenced immediately after intubation. Five and thirty minutes after intubation, $\mathrm{ABG}$ measurements were again performed ( $A B G 3$ and $A B G$ 4). At inclusion, and 5 and 30 minutes after intubation, blood samples were taken for culture. Troponin Ic levels were sampled at inclusion and six hours after intubation. Thirty minutes after intubation, endotracheal aspiration was performed on all patients. VT: tidal volume.

Novametrix, Wallingford, CT, USA). Arterial blood gases were sampled before intubation, and within 2, 5, and 30 minutes after intubation. All patients were equipped with a radial or femoral arterial catheter (Arrow Inc., Erding, Germany). Blood pressure was recorded continuously throughout the study. Troponin Ic was measured at inclusion (before intubation) and six hours after intubation. Samples for blood cultures (aerobic and anaerobic) were taken at study inclusion, and 5 minutes and 30 minutes after intubation. An endotracheal aspirate was also performed, for bacteriological analysis, 30 minutes after intubation. According to our institution protocol, a chest $\mathrm{x}$-ray was performed after intubation of all patient.

\section{Endpoints and statistical analysis}

The primary endpoint was the $\mathrm{PaO}_{2}$ value obtained five minutes after tracheal intubation. We used data from a previous study to calculate required patient numbers [8]. In the study by Baillard and colleagues [8], the average $\mathrm{PaO}_{2}$ at five minutes after intubation was $124 \mathrm{mmHg}$ (range, 70 to $183 \mathrm{mmHg}$ ). We calculated that at least 14 patients would be required in each group to allow analysis of a $100 \%$ increase in mean $\mathrm{PaO}_{2}$, assuming an $\alpha$ risk of 0.05 and a $\beta$ risk of 0.8 . Secondary endpoints were $\mathrm{PaO}_{2}$ at 30 minutes after intubation, haemodynamic and microbiological safety, ICU length of stay, ICU mortality, and mechanical ventilation duration. Nonparametric data were analysed using Mann-Whitney U tests. For nominal data, we used chi-squared analysis or Fisher's exact test, as appropriate. Comparison of $\mathrm{PaO}_{2}$ levels at different times was performed using two-way analysis of variance with Bonferroni correction. Data are expressed as median values (with interquartile ranges) or as mean \pm standard deviation. Statistical analysis was performed using the software package StatView (Abacus Inc., Berkeley, CA, USA).

\section{Results}

Between September 2007 and September 2008, 67 patients required orotracheal intubation in our ICUs (Figure 2). Twenty-one patients were intubated for reasons other than acute respiratory failure (e.g., neurologic causes and cardiac arrest). Consequently, 44 consecutive patients who met the study inclusion criteria were enrolled (no patient refused to participate). Four patients were withdrawn and were not included in the analysis (three before intubation and one after intubation). Thus, 20 patients were evaluated in each of the control and RM groups.

The baseline characteristics of the two groups were similar in terms of age, disease severity, organ failure, and diagnosis on admission (Table 1). Arterial blood gas levels and oxygen supply were also similar between the two groups. Before inclusion, six and seven patients in the control and RM groups, respectively, had received at least one ineffective trial of NIV for first-line treatment of acute respiratory failure. The intubation difficulty scale was similar between the two groups (easy 14 vs 16; 


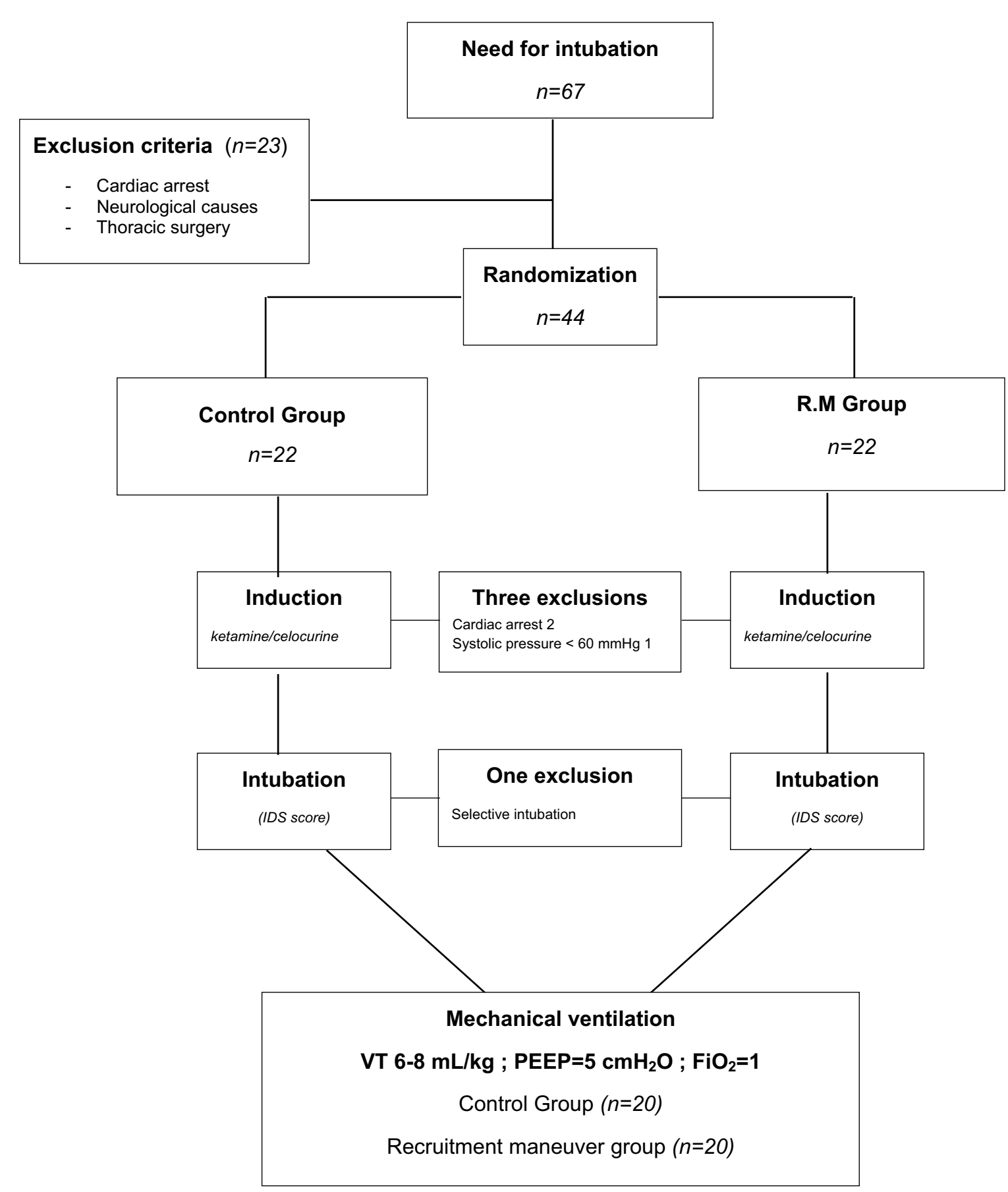

Figure 2 Flow chart of the study. From September 2007 to September 2008, 67 patients required tracheal intubation. Twenty-three patients were intubated for reasons other than acute respiratory failure. The remaining 44 patients were thus randomized to our two groups. Three patients were excluded before intubation because of cardiac arrest after induction $(n=2)$ or systolic blood pressure below $50 \mathrm{mmHg}$. The two patients excluded for cardiac arrests were patients with severe hypoxemia. Blood gases at inclusions were partial pressure of arterial oxygen $\left(\mathrm{PaO}_{2}\right) 37 \mathrm{mmHg}$, partial pressure of arterial carbon dioxide $\left(\mathrm{PaCO}_{2}\right) 22 \mathrm{mmHg}, \mathrm{pH} 7.11$, serum potassium 3.9 for the first patient and $\mathrm{PaO}_{2} 41 \mathrm{mmHg}, \mathrm{PaCO} 233 \mathrm{mmHg}, \mathrm{pH} 7.26$, serum potassium 4.1 for the second. In both cases, cardiac arrests were recovered after cardiopulmonary resuscitation. One patient was excluded because of selective intubation. Forty patients were thus ultimately included in the study. $\mathrm{FiO}_{2}$ : fraction of inspired oxygen; IDS: intubation difficult scale; PEEP: positive end-expiratory pressure; VT: tidal volume. 
Table 1: Clinical characteristics of patients at inclusion

\begin{tabular}{lccc}
\hline & $\begin{array}{c}\text { Control group } \\
(\mathbf{n}=\mathbf{2 0})\end{array}$ & $\begin{array}{c}\text { RM group } \\
(\mathbf{n}=\mathbf{2 0})\end{array}$ & $\boldsymbol{P}$ \\
\hline Age (years) & $67 \pm 8$ & $62(9)$ & 0.19 \\
Gender (F/M) & $7 / 13$ & $5 / 15$ & 0.73 \\
Height (cm) & $167 \pm 6$ & $172 \pm 8$ & 0.09 \\
Weight (kg) & $72 \pm 18$ & $74 \pm 10$ & 0.66 \\
SAPS II score [16] & $48 \pm 18$ & $44 \pm 23$ & 0.49 \\
Knaus class A/B/C/D (no.) [18] & $2 / 8 / 6 / 4$ & $3 / 9 / 6 / 2$ & 0.8 \\
McCabe score 1/2/3 (no.) [17] & $5 / 10 / 5$ & $4 / 10 / 6$ & 0.9 \\
Diagnosis & 10 & & 11 \\
Pneumonia (no.) & 6 & 7 & 2 \\
Extra pulmonary ALI (no.) & 4 & \\
Other (no.) & & & \\
\hline ALl: acute lung injury; F: female; M: male; RM: recruitment manoeuvre; SAPS II: simple acute physiologic score II. \\
Chi-squared for overall diagnoses: $P=0.673$.
\end{tabular}

slightly difficult $6 v s$, in the control and RM groups, respectively). There was no significant difference between groups in terms of mechanical ventilation duration or ICU length of stay.

\section{Gas exchange}

As shown in Table 2, there were no differences in terms of $\mathrm{PaO}_{2}$, partial pressure of carbon dioxide $\left(\mathrm{PaCO}_{2}\right)$, or blood $\mathrm{pH}$, either at admission or after tracheal intubation. In the RM group, $\mathrm{RM}$ increased $\mathrm{PaO}_{2}$ by $181 \%$ at 5 minutes and by $114 \%$ at 30 minutes after intubation $(P<$ $0.0001)$. However, in the control group, $\mathrm{PaO}_{2}$ did not significantly change (-4\% 5 minutes after and $+11 \% 30$ minutes after intubation).

Thirteen patients were under NIV at inclusion. These patients (six in the control group and seven in the RM group) were preoxygenated with NIV. As shown in Figure 3 , there was no significant difference in $\mathrm{PaO}_{2}$ before preoxygenation or immediately after intubation for patients who underwent conventional or NIV preoxygenation. Values ranged from 87 (77 to 96 ) to 96 (83 to 130 ) $\mathrm{mmHg}$ in conventional preoxygenation patients $(\mathrm{n}=27 ; \mathrm{P}=$ 0.48 ), and from 78 (71 to 90 ) to 81 (63 to 96$) \mathrm{mmHg}$ in those treated with NIV preoxygenation $(\mathrm{n}=13 ; P=0.34)$. During intubation, $\mathrm{SpO}_{2}$ decreased from $92 \pm 4 \%$ to $88 \pm$ $9 \%$ in the control group and from $91 \pm 5 \%$ to $89 \pm 12 \%$ in the RM group $(P=0.23)$.

\section{Haemodynamic data and troponin Ic levels}

There were no between-group differences in haemodynamic conditions at any time during the study (Table 3). During the RM, systolic arterial pressure decreased from $106 \pm 23 \mathrm{mmHg}$ to $96 \pm 34 \mathrm{mmHg}$. In one patient, the RM was interrupted because the systolic blood pressure decreased to less than $60 \mathrm{mmHg}$. After interruption of the RM, blood pressure increased from 55 to $110 \mathrm{mmHg}$ within 15 seconds. No patient showed a heart rate decrease of more than $20 \%$ during the RM. Troponin Ic levels were $0.1 \pm 0.1 \mathrm{ng} / \mathrm{mL}$ and $0.2 \pm 0.3 \mathrm{ng} / \mathrm{mL}$ before intubation, and $0.2 \pm 0.2 \mathrm{ng} / \mathrm{mL}$ and $0.2 \pm 0.3 \mathrm{ng} / \mathrm{mL}$ six hours after intubation, respectively, in the control and RM groups $(P=0.7)$; there were no significant increases after intubation in either group $(+0.04 \mathrm{ng} / \mathrm{mL}$ in the $\mathrm{RM}$ group and $+0.06 \mathrm{ng} / \mathrm{mL}$ in the control group, $P=0.8)$. No change in electrocardiographic output was detected in any patient over the entire study period. No pneumothorax was seen on chest X-ray.

\section{Bacteriological analysis}

Blood samples were obtained from all patients. Eight patients had positive endotracheal aspirates without positive blood cultures (five in the RM group and three in the control group). Data on all patients with positive blood cultures are summarized in Table 4. Following intubation, 15 of 40 patients showed positive blood culture (RM group $n=7$; control group $n=6$ ). One patient in each group had positive blood cultures before and after intubation. In each instance, the endotracheal aspirate was positive for, at a minimum, the microorganisms isolated from the blood of culture-positive patients. In the 13 such patients, 6 had no history of pneumonia either before or after intubation.

\section{Discussion}

The major finding of the present study is that a RM consisting of a CPAP of $40 \mathrm{cmH}_{2} \mathrm{O}$ delivered over 30 seconds is safe and efficiently reduces short-term hypoxemia following intubation in critically ill hypoxemic patients. To the best of our knowledge, this study is the first to evalu- 


\begin{tabular}{|c|c|c|c|c|}
\hline & Before intubation & $\begin{array}{c}30 \text { seconds after } \\
\text { intubation }\end{array}$ & $\begin{array}{c}5 \text { minutes after } \\
\text { intubation }\end{array}$ & $\begin{array}{l}30 \text { minutes after } \\
\text { intubation }\end{array}$ \\
\hline \multicolumn{5}{|l|}{ pH } \\
\hline Control group $(n=20)$ & $7.27 \pm 0.1$ & $7.22 \pm 0.1$ & $7.22 \pm 0.2$ & $7.27 \pm 0.1$ \\
\hline RM group $(n=20)$ & $7.36 \pm 0.1$ & $7.29 \pm 0.1$ & $7.29 \pm 0.1$ & $7.30 \pm 0.1$ \\
\hline \multicolumn{5}{|l|}{$\mathrm{PaCO} 2(\mathrm{mmHg})$} \\
\hline Control group $(n=20)$ & $49 \pm 12$ & $53 \pm 10$ & $52 \pm 8$ & $46 \pm 6$ \\
\hline RM group $(n=20)$ & $44 \pm 12$ & $54 \pm 15$ & $51 \pm 12$ & $51 \pm 11$ \\
\hline \multicolumn{5}{|l|}{$\mathrm{PaO2}(\mathrm{mmHg})$} \\
\hline Control group $(n=20)$ & $79(73-87)$ & $89(78-116)$ & $85(74-109)$ & $95(82-125)$ \\
\hline RM group $(n=20)$ & $73(63-92)$ & $71(56-105)$ & $246(128-303)^{* \#}$ & $171(119-241)^{* \#}$ \\
\hline \multicolumn{5}{|l|}{$\mathrm{SaO2}(\%)$} \\
\hline Control group $(n=20)$ & $94 \pm 4$ & $93 \pm 4$ & $92 \pm 5$ & $96 \pm 4$ \\
\hline RM group $(n=20)$ & $92 \pm 5$ & $90 \pm 9$ & $97 \pm 3^{* \#}$ & $97 \pm 3$ \\
\hline
\end{tabular}

All $\mathrm{PaO}_{2}$ values were sampled at a fraction of inspired oxygen of 1, except before intubation, when oxygen flow delivery was 10 to $15 \mathrm{~L} / \mathrm{min}$. Data are presented as means \pm standard deviation. ${ }^{*} P<0.05$ compared with the value obtained before intubation. $\# P<0.05$ for a difference between groups. All data are mean \pm standard deviation expect for $\mathrm{PaO}_{2}$ median (75-25).

$\mathrm{PaCO}_{2}$ : partial pressure of arterial carbon dioxide; $\mathrm{PaO}_{2}$ : partial pressure of arterial oxygen; $\mathrm{RM}$ : recruitment manœuvre; SaO 2 : arterial oxygen saturation.

ate the short-term effects of a RM immediately after intubation on gas exchange, haemodynamic variables, and bacteriological effects in such patients.

Induction of general anesthesia and mechanical ventilation affect lung volume and gas exchange, even in patients with healthy lungs. In addition, when invasive ventilation is initiated to manage acute respiratory failure, underlying lung disease (associated with limited alveolar volume and an increased shunt fraction) increases the risk of alveolar collapse. Mechanical ventilation with PEEP reduces ventilation-induced lung collapse $[20,21]$. However, both animal and clinical studies have shown that PEEP is not able to 're-open' non-ventilated lung areas [22-24] except when PEEP is used as an extended sigh $[9,12]$. Several reports have described the positive effects of RMs on lung collapse in both anesthetized and acute respiratory distress syndrome (ARDS) patients [9,25-27]. In critically ill patients with acute lung injury or ARDS, those who show a positive response to a RM procedure are characterized by diffuse loss of aeration and early onset of mechanical ventilation $[9,28]$. Some authors have suggested the potential benefit of a RM performed early after intubation in the operating theatre [29]. From a physiological perspective, a RM is the obvious answer to changes in respiratory parameters induced by 'rapid sequence induction'.

We did not compare lung volume between the two groups, but the increase in $\mathrm{PaO}_{2}$ after $\mathrm{RM}$ is probably attributable, at least in part, to alveolar recruitment. Such recruitment is an anatomical phenomenon depending exclusively on penetration of gas into poorly aerated or non-aerated lung regions, whereas arterial oxygenation is a complex physiologic parameter affected by multiple factors such as the extent of lung aeration, regional pulmonary flow, cardiac index, and oxygen delivery. In the present study, during which hemodynamic conditions were constant, changes in $\mathrm{PaO}_{2}$ were acceptable surrogates of recruited volume.

Concerns have been raised about the potential risk of hemodynamic impairment during RMs [30-32]. In the present study, only one patient experienced a transient decrease in blood pressure. The explanation for such stability is complex. First, according to French guidelines, a fluid challenge was administered to all patients before rapid sequence induction, to avoid hypovolemia [33]. Second, RM-induced hypotension has been reported in patients with focal ARDS and/or late acute lung injuryARDS $[12,28]$. By definition, our patients were at the early stage of acute lung injury and rapid sequence induction-induced atelectasis represents a diffuse loss of aeration. These two features partly explain our results. The effect of a RM on arterial pressure and cardiac output include reduced preload owing to transmission of airway pressure to the intrathoracic vasculature, and/or an increased afterload attributable to increased lung volume $[34,35]$. In patients with a stiff chest wall, the degree of airway pressure transmitted to the pleural space would be larger than in patients with a normal chest wall; thus, the 

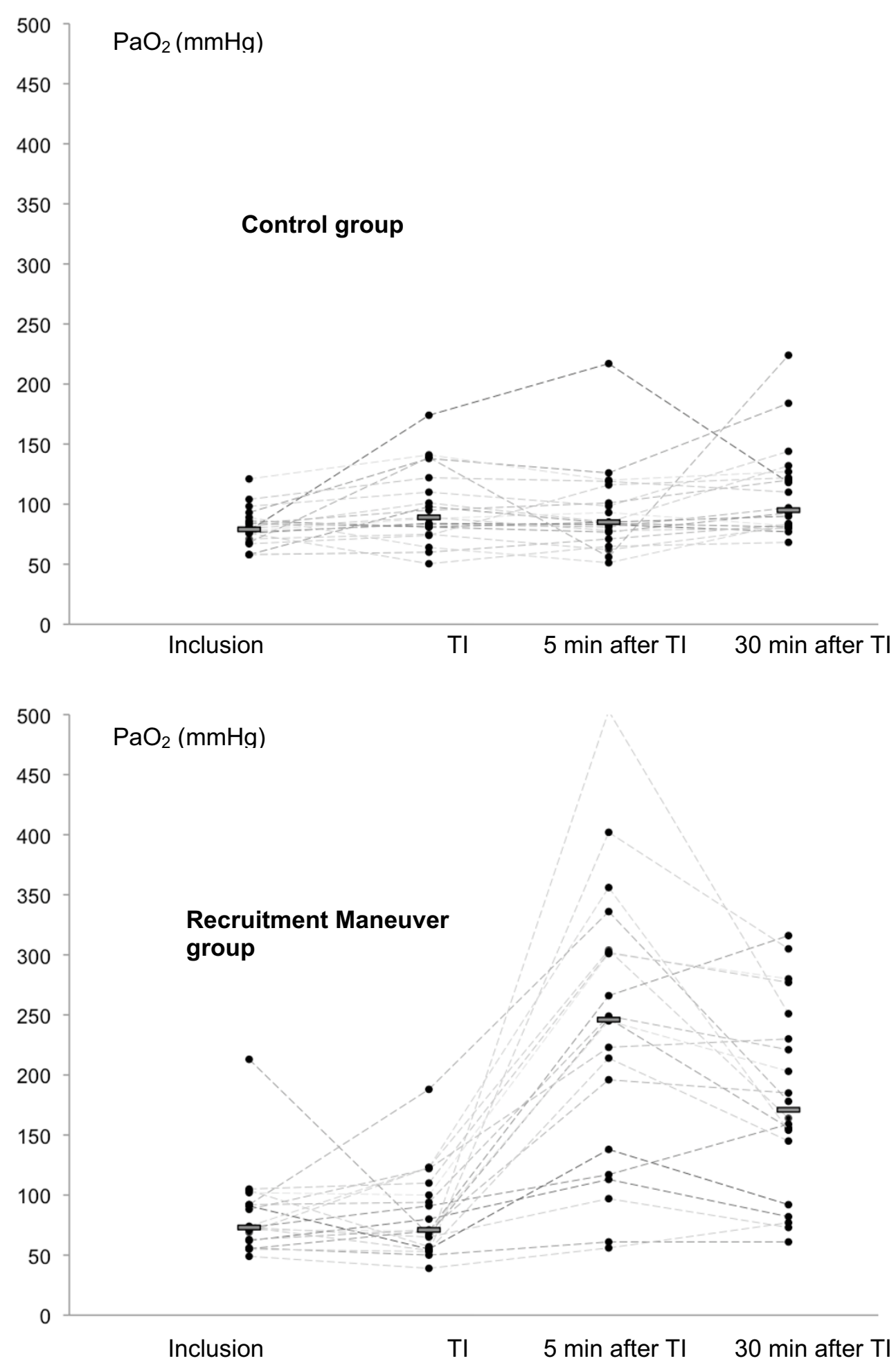

Figure 3 Individual $\mathrm{PaO}_{2}$ values at different study times. Individual partial pressure of arterial oxygen $\left(\mathrm{PaO}_{2}\right)$ at inclusion, immediately after intubation (TI), 5 minutes after intubation, and 30 minutes after intubation of patients in the control group (top), and RM group (bottom). A full circle represents an individual value. Bars represent median values. One patient had a $\mathrm{PaO}_{2}$ of $504 \mathrm{mmHg}$ after RM. These data are not shown in the Figure. 
Table 3: Hemodynamic data at different study times

\begin{tabular}{|c|c|c|c|c|}
\hline & Before intubation & $\begin{array}{c}30 \text { seconds after } \\
\text { intubation }\end{array}$ & $\begin{array}{c}5 \text { minutes after } \\
\text { intubation }\end{array}$ & $\begin{array}{l}30 \text { minutes after } \\
\text { intubation }\end{array}$ \\
\hline \multicolumn{5}{|l|}{ HR } \\
\hline Control group $(n=20)$ & $113 \pm 19$ & $104 \pm 20$ & $107 \pm 15$ & $107 \pm 15$ \\
\hline RM group $(n=20)$ & $103 \pm 19$ & $98 \pm 16$ & $98 \pm 16$ & $97 \pm 4$ \\
\hline \multicolumn{5}{|l|}{ SAP $(\mathbf{m m H g})$} \\
\hline Control group $(n=20)$ & $120 \pm 20$ & $103 \pm 38$ & $114 \pm 20$ & $123 \pm 28$ \\
\hline RM group $(n=20)$ & $133 \pm 25$ & $106 \pm 23$ & $107 \pm 23$ & $111 \pm 14$ \\
\hline \multicolumn{5}{|l|}{ MAP $(\mathrm{mmHg})$} \\
\hline Control group $(n=20)$ & $82 \pm 11$ & $70 \pm 25$ & $80 \pm 12$ & $86 \pm 19$ \\
\hline RM group $(n=20)$ & $93 \pm 15$ & $74 \pm 17$ & $74 \pm 17$ & $78 \pm 9$ \\
\hline \multicolumn{5}{|l|}{$\mathrm{DAP}(\mathrm{mmHg})$} \\
\hline Control group $(n=20)$ & $65 \pm 12$ & $53 \pm 20$ & $60 \pm 11$ & $64 \pm 15$ \\
\hline RM group $(n=20)$ & $70 \pm 13$ & $58 \pm 13$ & $58 \pm 13$ & $58 \pm 8$ \\
\hline
\end{tabular}

DAP: diastolic arterial pressure; HR: heart rate; MAP: mean arterial pressure; SAP: systolic arterial pressure.

decrease in the pressure gradient for venous return observed during application of RM might explain the reduction in cardiac output [36,37]. Patients with stiff chest walls are usually ventilated for more than seven days [28]; however, that was not the case in our study.

Our data indicate that the between-group difference in $\mathrm{PaO}_{2}$ decreased 30 minutes after RM. It must be emphasized that, for methodological reasons, the PEEP level was set at $5 \mathrm{cmH}_{2} \mathrm{O}$ throughout the study. This PEEP level was probably insufficient to avoid alveolar derecruitment and therefore decreased the RM effect [23].

The potential risk of RM-induced bacterial translocation has been discussed previously [24,38]. Several investigators have studied such translocation through the lungs [39-42] of animal models. Verbrugge and colleagues demonstrated that mechanical ventilation with a peak inspiratory pressure of $30 \mathrm{cmH}_{2} \mathrm{O}$, without PEEP, induced growth of Klebsiella pneumoniae bacteremia after three hours [39]. In that study blood cultures were only obtained after three hours of mechanical ventilation. Therefore, the onset of bacterial dissemination in their experimental model could not be determined. Addition of PEEP to mechanical ventilation reduces bacterial translocation. Cakar and colleagues also showed that high inflation pressures $\left(45 \mathrm{cmH}_{2} \mathrm{O}\right.$ positive inspiratory pressure (PIP)) without PEEP caused dissemination of intratracheally inoculated bacteria into the systemic circulation in rats [41]. However, in the cited study, repetitive RMs ( $45 \mathrm{cmH}_{2} \mathrm{O}$ CPAP for 30 seconds every 15 minutes for 2 hours) did not cause translocation of bacteria. Nahum and colleagues showed that over-distention of the lungs resulted in bacterial translocation and increased lung injury in dogs [40]. In the cited study, the highest transpulmonary pressure in the low-PEEP group (PIP of $35 \mathrm{cmH}_{2} \mathrm{O}$ and PEEP of $3 \mathrm{cmH}_{2} \mathrm{O}$ ) was associated with the earliest positive blood culture, at 30 minutes. Furthermore, the number of animals that developed positive blood cultures in this group was more than in other groups (ventilated with $13 \mathrm{cmH}_{2} \mathrm{O}$ PIP and $3 \mathrm{cmH}_{2} \mathrm{O}$ PEEP, or $30 \mathrm{cmH}_{2} \mathrm{O}$ PIP and $10 \mathrm{cmH}_{2} \mathrm{O}$ PEEP). In the same study, PEEP had a protective effect on bacteremia, despite lung over-distention. Unfortunately, no clinical data on this topic have been published to date. In our study, positive blood culture following intubation occurred in more than $30 \%$ of patients, showing the same microorganisms as found in endotracheal aspirates. There was no difference between groups, suggesting a possible causal role for mechanical ventilation in this phenomenon.

\section{Study limitations}

As our study could not be performed in a blinded fashion, we chose instead to minimize bias by distancing the investigators from clinical decisions made for included patients. However, it was sometimes necessary, in emergency circumstances, for study investigators to serve in primary clinician teams caring for study participants. Also, the number of patients is small and the results are thus limited to the spectrum of causes of acute respiratory failure presented in the present study. Chronic obstructive pulmonary disease exacerbation and cardiogenic shock were not exclusion criteria but these patients were most often admitted in a third ICU of our institution. During the study period, no patient with these conditions was enrolled in the study. Our results can not be extrapolated to these causes of respiratory failure. Six patients in the RM group and seven in the control group 
Table 4: Bacteriological data obtained from the 19 patients with positive samples

\begin{tabular}{|c|c|c|c|c|}
\hline & \multicolumn{3}{|c|}{ Blood culture } & \multirow{2}{*}{$\begin{array}{c}\text { Endotracheal } \\
\text { aspirate } \\
30 \text { minutes after } \\
\text { intubation }\end{array}$} \\
\hline & Before intubation & $\begin{array}{c}5 \text { minutes after } \\
\text { intubation }\end{array}$ & $\begin{array}{l}30 \text { minutes after } \\
\text { intubation }\end{array}$ & \\
\hline \multicolumn{5}{|l|}{ Control group $(n=10)$} \\
\hline & --- & MRSA & MRSA & MRSA \\
\hline & --- & $\mathrm{P}$ aeruginosa & Paeruginosa & Paeruginosa \\
\hline & --- & --- & Paeruginosa & Paeruginosa \\
\hline & --- & Ecoli & Ecoli & E coli \\
\hline & --- & Kpneumoniae & Kpneumoniae & Kpneumoniae \\
\hline & Koxytoca & Koxytoca & --- & --- \\
\hline & --- & Calbicans & Calbicans & Calbicans \\
\hline & --- & --- & --- & MRSA \\
\hline & --- & --- & --- & Paeruginosa \\
\hline & --- & --- & --- & Kpneumoniae \\
\hline \multicolumn{5}{|l|}{$R M$ group $(n=13)$} \\
\hline & --- & Kpneumoniae & --- & Kpneumoniae \\
\hline & --- & --- & M moranii & Mmoranii \\
\hline & --- & Ecloacae & Ecloacae & Ecloacae \\
\hline & E coli & E coli & Ecoli & --- \\
\hline & --- & Lactobacillus & --- & Lactobacillus \\
\hline & --- & Calbicans & --- & Calbicans \\
\hline & --- & --- & MRSA & MRSA \\
\hline & --- & Paeruginosa & --- & Paeruginosa \\
\hline & --- & --- & --- & Efecium \\
\hline & --- & --- & --- & Kpneumoniae \\
\hline & --- & --- & --- & Paeruginosa \\
\hline & --- & & --- & Paeruginosa \\
\hline & --- & --- & --- & MRSA \\
\hline
\end{tabular}

Calbicans:Candida albicans; E cloacae: Enterobacter cloacae; E coli: Escherichia coli; Efecium: Enterococcus fecium; Koxytoca: Klebsiella oxytoca; $K$ pneumoniae: Klebsiella pneumoniae; M moranii: Morganella moranii; MRSA: methicillin-resistant Staphylococcus aureus; P aeruginosa: Pseudomonas aeruginosa.

were in NIV failure at time of study inclusion. These patients had been preoxygenated with NIV. Contrary to the results of Baillard and colleagues [8], these 13 patients did not show better $\mathrm{PaO}_{2}$ values immediately after intubation compared with patients who underwent a conventional preoxygenation procedure. We consider that the 13 patients were more severely ill, and thus more hypoxemic, than patients who were not under NIV at randomization. As the same numbers of patients were under NIV in either group, no NIV bias was introduced into our analysis.

Our results indicate hemodynamic stability during and after RM. Two methodological limitations for the interpretation of these results must be pointed out. First, we only use arterial blood pressure to assess hemodynamic conditions and we were not able to evaluate RM-induced changes in cardiac output. From a clinical point of view, it was difficult to measure cardiac output during and immediately after intubation. Second, ketamine was the exclusive hypnotic agent used in our ICUs for rapid sequence induction. As ketamine is well known for its favorable hemodynamic profile, our results cannot be extrapolated to settings in which other hypnotic agents are used for rapid sequence induction.

Our study presents a novel approach to initiation of mechanical ventilation in hypoxemic patients. However, it is not clear if our approach will improve clinical outcomes, and additional studies are warranted to determine 
the optimal role for the technique, the best mode of application, and effects on important clinical outcomes. Blood samples were only cultured from 5 minutes and $30 \mathrm{~min}$ utes after the RM. Animal investigations [39-41] indicate that it would be interesting to assess blood samples cultured for 30 minutes for at least 3 hours. Unfortunately, it is not possible to conduct this experiment for ethical reasons.

\section{Conclusions}

Lung collapse following tracheal intubation and anesthesia in hypoxemic patients is often a life-threatening condition. The use of RM appears safe and efficient, limiting the depth of short-term hypoxemia in our study population. Notwithstanding the effect of $\mathrm{RM}$ on $\mathrm{PaO}_{2}$ levels following intubation, the RM did not decrease desaturation during intubation. Preoxygenation with intubation followed by RM is an attractive treatment strategy that merits further study.

\section{Key messages}

- RM immediately after intubation are efficient to reduce short-term hypoxemia and appeared safe.

- RM could be used after intubation of hypoxemic patients to limit the depth and duration of hypoxemia.

\section{Abbreviations $\mathrm{RM}$ : recruitment maneuver; $\mathrm{SpO}_{2}$ : pulse oxymetry. \\ Competing interests \\ The authors declare that they have no competing interests.}

ARDS: acute respiratory distress syndrome; CPAP: continuous positive airway pressure; $\mathrm{FiO}_{2}$ : fraction of inspired oxygen; $\mathrm{NIV}$ : non invasive ventilation; $\mathrm{PaCO}_{2}$ : partial pressure of arterial carbon dioxide; $\mathrm{PaO}_{2}$ : partial pressure of arterial oxygen; PEEP: positive end-expiratory pressure; PIP: positive inspiratory pressure;

\section{Authors' contributions}

JMC and EF participated in the design of the study, carried out the study and drafted the manuscript. ALC, RG, and MJ participated in the design of the study, inclusion of patients and data analysis. SCC, DG, and SP participated in the study and study analysis. BJ, GC, SJ, and JEB participated in the design of the study and helped to draft the manuscript. All authors read and approved the final manuscript.

\section{Acknowledgements}

The authors thanks Dr Scott Butler for English editing, Dr JP Mission for statistical analysis, and the nurses and physicians of the Adult Intensive Care Unit of Clermont-Ferrand for patients care during the study. This work has been supported by the University Hospital of Clermont-Ferrand.

\section{Author Details}

${ }^{1}$ General ICU, Department of Anesthesiology and Critical-Care, Estaing Hospital, University Hospital of Clermont-Ferrand, 1 Place Lucie Aubrac, 63000 Clermont-Ferrand, France, ${ }^{2}$ Surgical ICU and Department of Anesthesiology, DAR B University Hospital of Montpellier, and Saint-Eloi Hospital, Montpellier University, 80 Avenue Augustin Fliche34000 Montpellier, France and 3MedicoSurgical ICU, Gabriel Montpied Hospital, University Hospital of ClermontFerrand, 58 Bd Montalambert, 63000 Clermont-Ferrand, France
Received: 22 November 2009 Revised: 10 February 2010

Accepted: 28 April 2010 Published: 28 April 2010

\section{References}

1. Schettino G, Altobelli N, Kacmarek RM: Noninvasive positive-pressure ventilation in acute respiratory failure outside clinical trials: experience at the Massachusetts General Hospital. Crit Care Med 2008, 36:441-447.

2. Jaber $S$, Jung B, Chanques $G$, Bonnet F, Marret E: Effects of steroids on reintubation and post-extubation stridor in adults: meta-analysis of randomised controlled trials. Crit Care 2009, 13:R49.

3. Langeron $\mathrm{O}$, Amour J, Vivien B, Aubrun F: Clinical review: management of difficult airways. Crit Care 2006, 10:243.

4. Hedenstierna G: Pulmonary perfusion during anesthesia and mechanical ventilation. Minerva Anestesiol 2005, 71:319-324.

5. Hernandez G, Pena H, Cornejo R, Rovegno M, Retamal J, Navarro JL, Aranguiz I, Castro R, Bruhn A: Impact of emergency intubation on central venous oxygen saturation in critically ill patients: a multicenter observational study. Crit Care 2009, 13:R63.

6. Sartorius A, Lu Q, Vieira S, Tonnellier M, Lenaour G, Goldstein I, Rouby JJ: Mechanical ventilation and lung infection in the genesis of air-space enlargement. Crit Care 2007, 11:R14

7. Fanelli V, Mascia L, Puntorieri V, Assenzio B, Elia V, Fornaro G, Martin EL, Bosco M, Delsedime L, Fiore T, Grasso S, Ranieri VM: Pulmonary atelectasis during low stretch ventilation: "open lung" versus "lung rest" strategy. Crit Care Med 2009, 37:1046-1053.

8. Baillard C, Fosse JP, Sebbane M, Chanques G, Vincent F, Courouble P, Cohen Y, Eledjam JJ, Adnet F, Jaber S: Noninvasive ventilation improves preoxygenation before intubation of hypoxic patients. Am J Respir Crit Care Med 2006, 174:171-177.

9. Constantin JM, Jaber S, Futier E, Cayot-Constantin S, Verny-Pic M, Jung B, Bailly A, Guerin R, Bazin JE: Respiratory effects of different recruitment maneuvers in acute respiratory distress syndrome. Crit Care 2008, 12:R50.

10. Frank JA, McAuley DF, Gutierrez JA, Daniel BM, Dobbs L, Matthay MA: Differential effects of sustained inflation recruitment maneuvers on alveolar epithelial and lung endothelial injury. Crit Care Med 2005, 33:181-188. discussion 254-255.

11. Rothen HU, Sporre B, Engberg G, Wegenius G, Hedenstierna G Reexpansion of atelectasis during general anaesthesia may have a prolonged effect. Acta Anaesthesio/ Scand 1995, 39:118-125.

12. Constantin JM, Cayot-Constantin S, Roszyk L, Futier E, Sapin V, Dastugue B, Bazin JE, Rouby JJ: Response to recruitment maneuver influences net alveolar fluid clearance in acute respiratory distress syndrome. Anesthesiology 2007, 106:944-951.

13. West JB: Invited review: pulmonary capillary stress failure. J App/ Physiol 2000, 89:2483-2489. discussion 2497

14. Hotchkiss JR Jr, Blanch L, Naveira A, Adams AB, Carter C, Olson DA, Leo PH, Marini JJ: Relative roles of vascular and airspace pressures in ventilatorinduced lung injury. Crit Care Med 2001, 29:1593-1598.

15. Piacentini E, Villagra A, Lopez-Aguilar J, Blanch L: Clinical review: the implications of experimental and clinical studies of recruitment maneuvers in acute lung injury. Crit Care 2004, 8:115-121.

16. Le Gall JR, Lemeshow S, Saulnier F: A new Simplified Acute Physiology Score (SAPS II) based on a European/North American multicenter study. JAMA 1993, 270:2957-2963.

17. McCabe W, Jackson G: Gram-negative bacteremia. Etiology and ecology. Arc Int Med 1963, 110:845-857.

18. Knaus WA, Zimmerman JE, Wagner DP, Draper EA, Lawrence DE: APACHEacute physiology and chronic health evaluation: a physiologically based classification system. Crit Care Med 1981, 9:591-597.

19. Adnet F, Borron SW, Racine SX, Clemessy JL, Fournier JL, Plaisance $P$, Lapandry C: The intubation difficulty scale (IDS): proposal and evaluation of a new score characterizing the complexity of endotracheal intubation. Anesthesiology 1997, 87:1290-1297.

20. Neumann P, Rothen HU, Berglund JE, Valtysson J, Magnusson A, Hedenstierna G: Positive end-expiratory pressure prevents atelectasis during general anaesthesia even in the presence of a high inspired oxygen concentration. Acta Anaesthesiol Scand 1999, 43:295-301. 
21. Halter JM, Steinberg JM, Gatto LA, DiRocco JD, Pavone LA, Schiller HJ, Albert S, Lee HM, Carney D, Nieman GF: Effect of positive end-expiratory pressure and tidal volume on lung injury induced by alveolar instability. Crit Care 2007, 11:R20.

22. Koh WJ, Suh GY, Han J, Lee SH, Kang EH, Chung MP, Kim H, Kwon OJ: Recruitment maneuvers attenuate repeated derecruitment-associated lung injury. Crit Care Med 2005, 33:1070-1076.

23. Halter JM, Steinberg JM, Schiller HJ, DaSilva M, Gatto LA, Landas S, Nieman GF: Positive end-expiratory pressure after a recruitment maneuver prevents both alveolar collapse and recruitment/derecruitment. Am J Respir Crit Care Med 2003, 167:1620-1626.

24. Fan E, Wilcox ME, Brower RG, Stewart TE, Mehta S, Lapinsky SE, Meade MO, Ferguson ND: Recruitment maneuvers for acute lung injury: a systematic review. Am J Respir Crit Care Med 2008, 178:1156-1163.

25. Riva DR, Oliveira MB, Rzezinski AF, Rangel G, Capelozzi VL, Zin WA, Morales MM, Pelosi P, Rocco PR: Recruitment maneuver in pulmonary and extrapulmonary experimental acute lung injury. Crit Care Med 2008, 36:1900-1908.

26. Valente Barbas CS: Lung recruitment maneuvers in acute respiratory distress syndrome and facilitating resolution. Crit Care Med 2003, 31:S265-271.

27. Reis Miranda D, Struijs A, Koetsier P, van Thiel R, Schepp R, Hop W, Klein J, Lachmann B, Bogers AJ, Gommers D: Open lung ventilation improves functional residual capacity after extubation in cardiac surgery. Crit Care Med 2005, 33:2253-2258.

28. Grasso S, Mascia L, Del Turco M, Malacarne P, Giunta F, Brochard L, Slutsky AS, Marco Ranieri V: Effects of recruiting maneuvers in patients with acute respiratory distress syndrome ventilated with protective ventilatory strategy. Anesthesiology 2002, 96:795-802.

29. Whalen FX, Gajic O, Thompson GB, Kendrick ML, Que FL, Williams BA, Joyner MJ, Hubmayr RD, Warner DO, Sprung J: The effects of the alveolar recruitment maneuver and positive end-expiratory pressure on arterial oxygenation during laparoscopic bariatric surgery. Anesth Analg 2006, 102:298-305

30. Claesson J, Lehtipalo S, Bergstrand U, Arnerlov C, Winso O: Negative mesenteric effects of lung recruitment maneuvers in oleic acid lung injury are transient and short lasting. Crit Care Med 2007, 35:230-238

31. Vieillard-Baron A, Charron C, Jardin F: Lung "recruitment" or lung overinflation maneuvers? Intensive Care Med 2006, 32:177-178.

32. Miranda DR, Klompe L, Cademartiri F, Haitsma JJ, Palumbo A, Takkenberg $J$ J, Lachmann B, Bogers AJ, Gommers D: The effect of open lung ventilation on right ventricular and left ventricular function in lunglavaged pigs. Crit Care 2006, 10:R86.

33. Girault C, Auriant I, Jaber S: Field 5. Safety practices procedures for mechanical ventilation. French-speaking Society of Intensive Care. French Society of Anesthesia and Resuscitation. Ann Fr Anesth Reanim 2008, 27:e77-89.

34. Lim SC, Adams AB, Simonson DA, Dries DJ, Broccard AF, Hotchkiss JR, Marini JJ: Transient hemodynamic effects of recruitment maneuvers in three experimental models of acute lung injury. Crit Care Med 2004, 32:2378-2384

35. Nielsen J, Nilsson M, Freden F, Hultman J, Alstrom U, Kjaergaard J, Hedenstierna G, Larsson A: Central hemodynamics during lung recruitment maneuvers at hypovolemia, normovolemia and hypervolemia. A study by echocardiography and continuous pulmonary artery flow measurements in lung-injured pigs. Intensive Care Med 2006, 32:585-594.

36. Robotham JL, Takata M, Berman M, Harasawa Y: Ejection fraction revisited. Anesthesiology 1991, 74:172-183.

37. Romand JA, Shi W, Pinsky MR: Cardiopulmonary effects of positive pressure ventilation during acute lung injury. Chest 1995, 108:1041-1048.

38. Kacmarek RM, Kallet RH: Should recruitment maneuvers be used in the management of ALI and ARDS? Respir Care 2007, 52:622-631. discussion 631-635.

39. Verbrugge SJ, Sorm V, van 't Veen A, Mouton JW, Gommers D, Lachmann B: Lung overinflation without positive end-expiratory pressure promotes bacteremia after experimental Klebsiella pneumoniae inoculation. Intensive Care Med 1998, 24:172-177.

40. Nahum A, Hoyt J, Schmitz L, Moody J, Shapiro R, Marini JJ: Effect of mechanical ventilation strategy on dissemination of intratracheally instilled Escherichia coli in dogs. Crit Care Med 1997, 25:1733-1743.
41. Cakar N, Akinci O, Tugrul S, Ozcan PE, Esen F, Eraksoy H, Cagatay A, Telci L, Nahum A: Recruitment maneuver: does it promote bacterial translocation? Crit Care Med 2002, 30:2103-2106

42. Lin CY, Zhang H, Cheng KC, Slutsky AS: Mechanical ventilation may increase susceptibility to the development of bacteremia. Crit Care Med 2003, 31:1429-1434.

doi: $10.1186 /$ cc8989

Cite this article as: Constantin et al., A recruitment maneuver increases oxygenation after intubation of hypoxemic intensive care unit patients: a randomized controlled study Critical Care 2010, 14:R76

\section{Submit your next manuscript to BioMed Central and take full advantage of:}

- Convenient online submission

- Thorough peer review

- No space constraints or color figure charges

- Immediate publication on acceptance

- Inclusion in PubMed, CAS, Scopus and Google Scholar

- Research which is freely available for redistribution

Submit your manuscript at www.biomedcentral.com/submit
C) Biomed Central 